\title{
Erratum to: A strong invariance principle for nonconventional sums
}

\section{Yuri Kifer}

Published online: 21 February 2013

(C) Springer-Verlag Berlin Heidelberg 2013

\section{Erratum to: Probab. Theory Relat. Fields DOI 10.1007/s00440-011-0404-1}

In order to produce parameters for which the approximation estimate (3.30) holds true (i.e. in order to ensure that the right hand sides of (3.29) form a converging series), as well as to satisfy other estimates in Sects. 3 and 4, the condition (2.18) in Assumption 2.1 should be written as

$$
\sum_{r=0}^{\infty} r^{\frac{16}{\delta}} \beta_{q}^{\delta}(r)<\infty
$$

The online version of the original article can be found under doi:10.1007/s00440-011-0404-1.

\section{Y. Kifer $(\varangle)$}

Institute of Mathematics, Hebrew University, 91904 Jerusalem, Israel

e-mail: kifer@math.huji.ac.il 